\title{
Índice DEC: una herramienta para valorar el desarrollo de los servicios sociales
}

\section{Gustavo García Herrero}

Asociación de Directoras y Gerentes de Servicios Sociales

<aitavo.gg@gmail.com>

Badira pobrezia- eta desberdintasun-maila edo biztanleriaren premia sozialak neurtzen dituzten azterlan batzuek. Baina Gizarte Zerbitzuen Garapenaren indizea bakarra da neurtu eta ebaluatzen egituren garapena eta gizartezerbitzuetako sistemaren aurrekontuak. Artikulu honetan azaltzen da ekimen hori nola sortu zuten; nola definitzen den gizarte-zerbitzuen garapena izaera operatiboko terminoetan; zeintzuk diren Indizea, ebaluazio-eskala eta informazio-iturrietan zehazturiko edukiak; eta aztertzen dira bere ahultasun eta hobekuntzarako erronkak. Azkenik, azaltzen da lurralde bakoitzeko administrazio bakoitzak eginiko murrizketen dimentsioa, eta baita ere prestazio eta zerbitzuen estaldura-adierazle desberdinek joandako hiru urteotan izandako eboluzioa.

\section{GAKO-HITZAK:}

Adierazleak, gizarte-zerbitzuak, estaldura, gastua, murrizketak.
Existen diversos estudios que miden la pobreza y la desigualdad, o determinados aspectos relacionados con las necesidades sociales de la población. Pero el Índice DEC es el único que trata de medir y evaluar el desarrollo de las estructuras y presupuestos del sistema de servicios sociales. En el presente artículo, se explica cómo surge esta iniciativa; cómo se define en términos operativos el desarrollo del sistema de servicios sociales; cuáles son los contenidos detallados del Îndice, su escala de valoración y sus fuentes de información; y se analizan sus debilidades y retos de mejora. Por último, se exponen los resultados de su aplicación en 2014, en los que destaca la dimensión de los recortes en cada territorio y en cada una de las administraciones, así como la evolución de los diferentes indicadores de cobertura de prestaciones y servicios en los tres últimos años.

\section{Palabras Clave:}

Índice, servicios sociales, cobertura, gasto, recortes. 


\section{Introducción}

Cualquier profesional que haya tenido que evaluar servicios sociales conoce bien las dificultades que ello entraña. Por eso, es posible que haya quien califique de osadía el intento de 'medir' el desarrollo global del sistema de servicios sociales. Y sin duda lo es. Somos conscientes de ello y lo fuimos cuando nos planteamos ese reto en 2011. Pero también sabíamos la importancia de tener una herramienta que permitiera medir y valorar el desigual desarrollo de los servicios sociales en los diferentes territorios. Si bien es cierto que existían diversos estudios para medir y valorar la pobreza y la desigualdad, o determinados aspectos relacionados con las necesidades sociales de la población, ninguno medía y evaluaba el desarrollo de las estructuras y presupuestos del sistema de servicios sociales.

\section{Cómo se construyó el Îndice DEC}

\subsection{Iniciativa}

Para ubicar la gestación del Índice DEC, conviene presentar brevemente la organización que asume la iniciativa y la lleva a cabo, la Asociación de Directoras y Gerentes de Servicios Sociales, una entidad sin ánimo de lucro, nacida en 1994 con el objetivo de impulsar la reflexión, el debate y la innovación en el ámbito de los servicios sociales. Para lograrlo, optamos por unas estructuras simples, que permitieran destinar todas nuestras energías a las tareas que motivan nuestra existencia, y no a gestionar la propia organización. Nuestras reflexiones y debates están siempre abiertos a toda persona que quiera participar, y valoramos la discrepancia como algo necesario y apreciado para avanzar en estas reflexiones.

Así, hemos abordado debates y elaboraciones novedosas: desde las nuevas tecnologías a la calidad, desde el urbanismo como espacio de la convivencia hasta los derechos subjetivos y su protección jurídica, el desarrollo legislativo o la economía de los servicios sociales. Especialmente conocidas son nuestras elaboraciones en torno a la aprobación, en su momento, de la Ley de la Dependencia y el seguimiento de su aplicación desde el Observatorio de la Dependencia, con dictámenes semestrales; los informes anuales sobre el estado social de la nación; los informes sobre el gasto en servicios sociales; sobre lo social y lo sanitario; sobre la Reforma Local; y, por supuesto, el Índice DEC. Toda nuestra producción es de acceso libre y gratuito ${ }^{1}$.

Proclamamos nuestro empeño en ser independientes, una condición sin la cual nuestros informes y dictámenes carecerían de credibilidad. Para garantizar nuestra independencia, hemos renunciado desde siempre a solicitar subvenciones. Ello nos obliga a contar exclusivamente con las cuotas de nuestros

${ }^{1}\langle$ http://www.directoressociales.com〉. socios y con colaboraciones que nos hacen llegar personas y organizaciones que comparten nuestros objetivos. A cambio, nadie de la propia asociación, ni de quienes participan en nuestros eventos o colaboran con nosotros cobra cantidad alguna por esa colaboración: ni por presentar una ponencia, ni por elaborar un documento, ni por ningún otro concepto.

Se trata, en suma, de una organización para la reflexión, el debate y la innovación. Una organización independiente, que ni solicita ni recibe subvenciones. Ése es el marco en el que se genera y se aplica, desde 2012, el Índice DEC.

Fue en nuestro XVII Congreso, en 2010, cuando se discutió y aprobó el diseño de un Índice para medir y valorar el desarrollo de los servicios sociales, acordando sus características y líneas generales, y constituyendo un grupo de trabajo para su elaboración. Este grupo planteó propuestas que fueron sometidas a la opinión y a las sugerencias de los miembros de la asociación y de diversas personas que, por su significación en el sector o por su interés, aportaron -espontáneamente o previa solicitud-sus opiniones a lo largo del proceso. Se llevó así una propuesta elaborada de Índice al XVIII Congreso de la Asociación (2011), que fue debatida y dejó diseñada la versión inicial del Îndice DEC.

A lo largo del proceso de elaboración del Índice, han participado más 200 profesionales cualificados. Una participación que se prolonga en una revisión crítica continuada tras cada una de sus aplicaciones, abierta igualmente a toda persona interesada. Este consenso en la fase de elaboración y tras cada una de sus aplicaciones, en un proceso de revisión continua, es lo que fundamenta y legitima el Índice DEC.

\subsection{Del concepto a su medición}

Evaluar el desarrollo de un sistema trasciende el ámbito de lo meramente cuantitativo, aunque utilice referencias objetivables y cuantificables, y aunque sus resultados se expresen, también, en una puntuación. Necesariamente requiere partir de un concepto de lo que se entiende por 'sistema de servicios sociales'; una dificultad de partida, porque, como es bien sabido, ni existe una norma básica que lo defina, ni una normativa o práctica homogénea en el conjunto de comunidades autónomas -que son las administraciones competentes para definir el sistema-, ni tan siquiera un consenso teórico o profesional al que recurrir. Por si era poco, se precisaba además definir de manera operativa las dimensiones del desarrollo de este sistema. Tampoco ninguna norma o consenso científico o profesional las define.

Éstos fueron los retos que tuvimos que afrontar al plantearnos el diseño de un Índice para medir y valorar el desarrollo de los servicios sociales en España. Sabíamos que teníamos que partir de unos conceptos que, como tales, son producto de una determinada manera de entender el sistema; sin pretender 
que el concepto que tomáramos como referencia fuera el único posible. Pero ello es inevitable siempre que se formula cualquier concepto que quiera expresar, en clave operativa, fenómenos complejos, como complejo es un sistema de servicios y su desarrollo.

Para abordar ese reto - definir el concepto de partida-, teníamos dos vías: acometer una profunda -y costosa- investigación previa; o partir de un consenso profesional. La primera vía superaba con mucho la capacidad de nuestra asociación; incluso supondría un reto técnico y económico de envergadura para cualquier organización pública o privada que decidiera abordarlo. Por eso optamos por el consenso profesional. Es a partir del consenso como se determinaron qué áreas o aspectos del desarrollo de los servicios sociales constituirían las referencias del Índice, su arquitectura básica sobre la que colocar los diferentes indicadores que permitieran su medición:

- Cómo se formula y reconoce el derecho a los servicios sociales (cuerpo legislativo y normativo), cómo se planifica y qué estructuras institucionales se establecen para su gestión: a este aspecto lo denominamos 'derechos y decisión política' y lo identificamos con la letra D.

- La inversión -el gasto- que las administraciones públicas realizan en esta materia: a este aspecto lo denominamos 'relevancia económica' y lo identificamos con la letra $\mathrm{E}$.

- Por último, los servicios y prestaciones que disponen para atender las necesidades de los/as ciudadanos: a este aspecto lo denominamos 'cobertura' y lo identificamos con la letra C.

El siguiente paso era ponderar cada uno de estos aspectos generales o áreas. Y en este empeño, las referencias para el consenso son menos precisas. Entendimos que la mayor puntuación debía otorgarse a la cobertura, ya que supone la efectiva materialización del sistema; al fin y al cabo, la planificación, la organización, las inversiones y el gasto tienen como finalidad garantizar servicios y prestaciones que hagan efectivos los derechos reconocidos. Convenimos, así, en otorgar a este apartado la mitad de los puntos de la escala (5 sobre 10). De las otras dos áreas, entendíamos que la relevancia económica debía tener más peso, al valorar el desarrollo del sistema, que sus referencias normativas, su planificación o sus estructuras gestoras, ya que es más directa su relación con la cobertura efectiva de prestaciones y servicios. De esa manera, otorgamos a esta área 3 de los 5 puntos restantes, dejando los otros 2 para puntuar los derechos y decisión política.

La estructura básica del Î́ndice quedaba así definida y ponderada:

- (D) Derechos y decisión política: hasta 2 puntos.

- (E) Relevancia económica: hasta 3 puntos.

- (C) Cobertura: hasta 5 puntos.
A este respecto, debemos señalar que, al revisar el Índice tras su aplicación en 2014, acordamos que, para su aplicación en 2015 , se ajustaría esta ponderación, dando más importancia a la cobertura (por encima de los 5 puntos) en detrimento de los derechos y decisión política (menos de 2), a la vista de la escasa incidencia que la legislación, la normativa y la planificación pueden llegar a tener, en ocasiones, sobre el desarrollo efectivo del sistema.

Definida y ponderada la estructura básica del Índice, el siguiente paso era determinar los indicadores que permitieran, de forma objetivable, llenar de contenidos cada una de las áreas. Definirlos y, por supuesto, ponderarlos. Una labor todavía más minuciosa y discutible, sin duda alguna. El resultado se mostrará con detalle más adelante, pero en líneas generales los indicadores que hemos contemplado en cada una de las áreas se describen seguidamente.

En derechos y decisión política (D), parece necesario contemplar la existencia de una ley que defina derechos subjetivos, un catálogo o cartera que los concrete y una planificación (plan estratégico o mapa) que exprese el compromiso institucional -con la consiguiente previsión presupuestaria- de dotar las estructuras prestacionales a través de las cuales se hagan efectivos estos derechos. Operativizar, a efectos del correspondiente indicador, cada uno de estos aspectos requiere referencias inequívocas y objetivables, que no pueden ser otras que las de la aprobación institucional. Así, no se valida ninguna ley, catálogo, cartera, plan o mapa que no haya sido aprobado en el correspondiente Gobierno o Parlamento autonómico y publicado en su boletín oficial. El apartado de derechos y decisión política se completa con un indicador que registra la inclusión del Sistema para la Autonomía y la Atención a la Dependencia (SAAD) en el de Servicios Sociales (quizás el menos ‘objetivable’ de todos los que contiene el Índice); y con una puntuación testimonial, que el Estatuto de Autonomía reconozca el derecho a los servicios sociales, y que el departamento que los gestiona en el Gobierno autonómico incluya el nombre de 'servicios sociales' (0,1 puntos. Por cierto, a fecha de hoy sólo en una comunidad autónoma, Baleares, se da esta circunstancia, algo muy significativo respecto a la escasa identidad del sector, cuando ni siquiera hay una denominación comúnmente aceptada).

La relevancia económica (E) se mide tanto en términos absolutos (gasto por habitante y año) como relativos (porcentaje de la riqueza -del PIB-que se dedica a servicios sociales y porcentaje que ese gasto en servicios sociales representa sobre el gasto total de las administraciones públicas del territorio). La referencia que nos permite el análisis de los presupuestos de las diferentes administraciones (central, autonómica y local) son los resultados del denominado 'gasto funcional 23 (servicios sociales y promoción social)', que elabora el Ministerio de Hacienda y Administraciones Públicas.

Finalmente, determinar indicadores para medir la cobertura (C) del sistema nos obliga a establecer de 
manera precisa su oferta de prestaciones y servicios. Una labor ya de por sí ardua y en la que no es fácil lograr el consenso entre los profesionales del sector, a la que se añade la dificultad para encontrar datos oficiales con los que construir indicadores relevantes. Con frecuencia, al presentar y debatir el Índice, hay personas que sugieren otros indicadores que medirían mejor la cobertura de determinados servicios o prestaciones; el problema radica en encontrar fuentes de información oficiales con la que construirlos. La ausencia o falta de calidad de las estadísticas oficiales en el sector, a la que luego haremos referencia, limita mucho las posibilidades de análisis. Con todo ello, éstas son las prestaciones y servicios del sistema que vamos a ponderar en el Índice, a través de los siguientes indicadores: estructuras básicas (personal de plantilla en los centros de servicios sociales), dependencia (cobertura y 'limbo'2), rentas mínimas de inserción (cobertura y cuantía), residencias para personas mayores (total de plazas y plazas públicas), ayuda a domicilio (cobertura e intensidad horaria), infancia (acogimientos familiares sobre el total de acogimientos), discapacidad (plazas residenciales, y plazas diurnas y ocupacionales), mujer (plazas de acogida) y personas sin hogar (plazas de alojamiento). Más adelante veremos el detalle de estos indicadores y su ponderación.

También en este aspecto la permanente revisión del Índice nos permite incorporar o matizar indicadores.
Así, tras su primera aplicación (2012) se sugirió que en el indicador de plazas residenciales para personas mayores, además del total, deberíamos ponderar de forma específica las de carácter público, algo que hacemos desde la edición de 2013. De la misma manera, se nos ha sugerido que incorporemos los centros de día de personas mayores y la teleasistencia como parte de la cobertura del sistema, y así se hará en la aplicación de 2015.

\subsection{Estructura y contenidos del Îndice DEC}

Como hemos visto, el Índice queda estructurado en tres áreas: derechos y decisión política (D), relevancia económica (E) y cobertura de servicios a la ciudadanía (C). Cada una de ellas engloba diversos indicadores, a los que se asigna una puntuación, cuya suma determina el resultado que cada comunidad obtiene en la correspondiente área y en el total. Asimismo, se establecen condiciones para alcanzar la 'excelencia' en cada una de estas tres áreas, que se simbolizan con la letra correspondiente en mayúsculas.

La conjunción de la excelencia alcanzada en cada una de las tres áreas y de la puntuación total resultante de la suma de los diferentes indicadores determina la calificación otorgada al desarrollo del sistema de servicios sociales en cada comunidad autónoma, de acuerdo con la escala de la Figura 1.

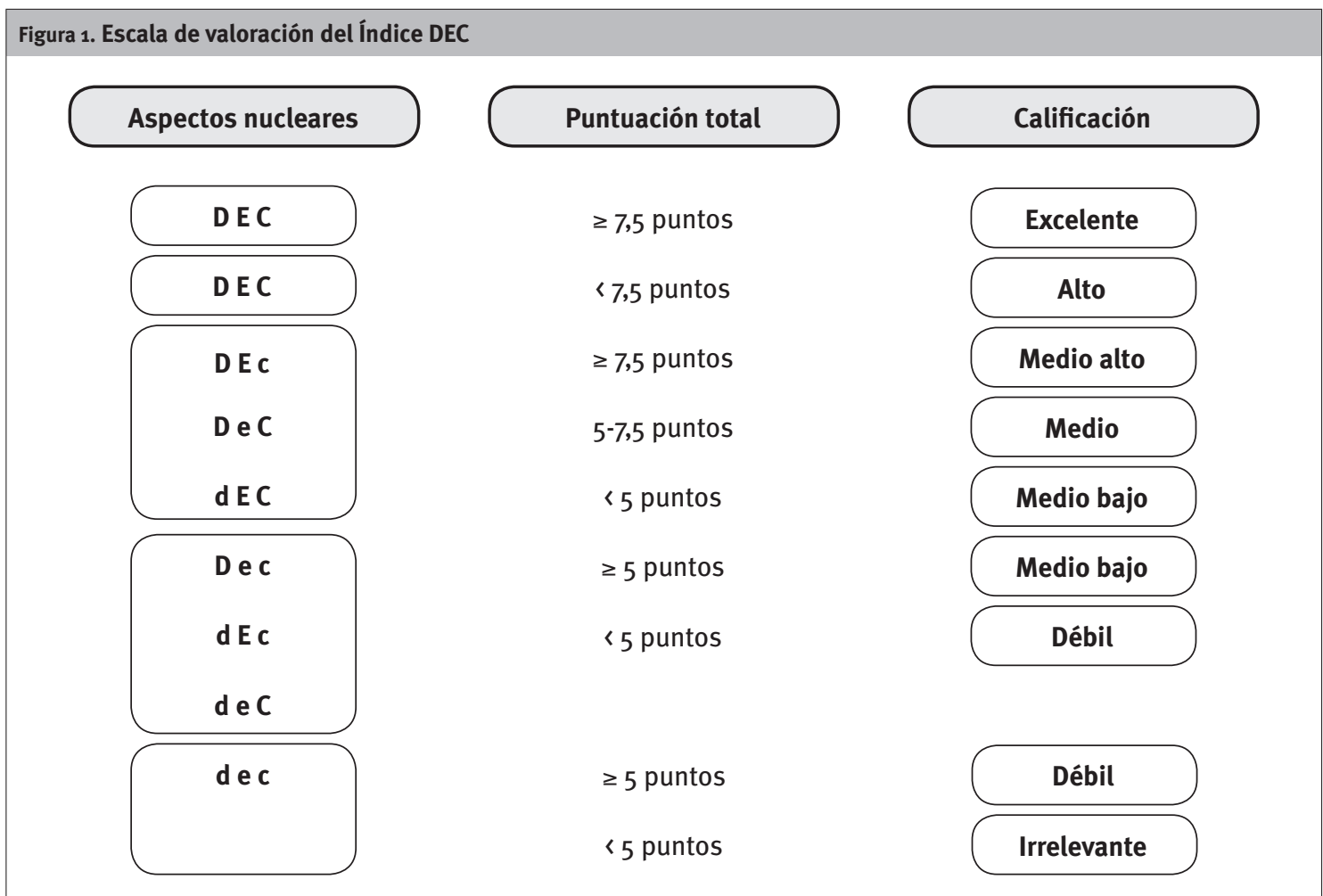

Fuente: García et al. (2014).

${ }^{2}$ Situación de las personas con dictámenes que dan derecho a prestación en el SAAD y están pendientes del programa individual de atención. 
Además, la aplicación del Îndice DEC en sucesivos años permite incorporar lo que denominamos 'perspectiva':

- Perspectiva positiva $(\mathrm{P}+)$ : comunidades autónomas que incrementan el gasto en servicios sociales, en términos absolutos y relativos (por habitante y año), de una a otra aplicación más de un $10 \%$; o menos de un $10 \%$, pero mejoran el valor en un número mayor de indicadores de cobertura que en los que empeoran.
- Perspectiva negativa (P-): comunidades autónomas que reducen el gasto en servicios sociales, en términos absolutos y relativos (por habitante y año), más de un $10 \%$ de una a otra aplicación; 0 menos de un $10 \%$, pero empeoran el valor en un número igual o mayor de indicadores de cobertura que en los que mejoran.

Los Cuadros 1, 2 y 3 recogen en detalle cada una de las tres áreas que contempla el Índice DEC, con sus correspondientes indicadores.

\begin{tabular}{|c|c|c|}
\hline \multicolumn{3}{|c|}{ Cuadro 1. Indicadores del Î́ndice DEC en el área de derechos y decisión política (D) } \\
\hline Indicador & Descripción & Puntuación* \\
\hline \multirow{3}{*}{$\begin{array}{l}\text { Ley específica de servicios sociales, con cartera } \\
\text { y catálogo }\end{array}$} & $\begin{array}{l}\text { Si tiene una ley que reconoce derechos subjetivos y establece la } \\
\text { obligatoriedad de concretarlos en una cartera o catálogo }\end{array}$ & 0,5 \\
\hline & $\begin{array}{l}\text { Si no ha desarrollado el catálogo o cartera de servicios en el plazo de } \\
\text { un año, o si no ha aprobado en ese mismo plazo un plan estratégico } \\
\text { de servicios sociales, o se encuentra caducado desde hace más de } \\
\text { un año }\end{array}$ & $-0,25$ \\
\hline & En caso de que no se hubiera desarrollado ni catálogo/cartera ni plan & $-0,35$ \\
\hline Catálogo o cartera publicados & $\begin{array}{l}\text { Si ha publicado el catálogo o cartera que desarrolla esos derechos en } \\
\text { forma de norma en boletín oficial }\end{array}$ & 0,5 \\
\hline $\begin{array}{l}\text { Sistema para la Autonomía y la Atención a la } \\
\text { Dependencia }\end{array}$ & $\begin{array}{l}\text { Si el SAAD está integrado en el sistema de servicios sociales y cuenta, } \\
\text { para ello, con los servicios de atención básica o comunitaria }\end{array}$ & 0,5 \\
\hline $\begin{array}{l}\text { Plan estratégico o mapa de cobertura aprobado } \\
\text { y con memoria económica }\end{array}$ & $\begin{array}{l}\text { Si se ha desarrollado y tiene vigente un plan estratégico o un mapa } \\
\text { de cobertura, con aprobación expresa en forma de norma o habiendo } \\
\text { pasado por el Parlamento, y que incluya memoria económica }\end{array}$ & 0,2 \\
\hline $\begin{array}{l}\text { Sistema de servicios sociales reconocido } \\
\text { como derecho de ciudadanía en el Estatuto de } \\
\text { Autonomía }\end{array}$ & $\begin{array}{l}\text { Si el Estatuto de Autonomía recoge el sistema de servicios sociales } \\
\text { como un derecho de ciudadanía en algún artículo, más allá de los } \\
\text { dedicados a materia competencial }\end{array}$ & 0,2 \\
\hline $\begin{array}{l}\text { Nombre de la consejería o departamento que } \\
\text { gestiona los servicios sociales }\end{array}$ & $\begin{array}{l}\text { Si se llama ‘de Servicios Sociales' y su principal competencia es la } \\
\text { gestión del sistema }\end{array}$ & 0,1 \\
\hline \multicolumn{2}{|l|}{ Puntuación máxima (total) } & 2,0 \\
\hline \multirow[b]{2}{*}{ Excelencia (D mayúscula) } & \multicolumn{2}{|c|}{$\begin{array}{l}\text { Es condición para alcanzar la excelencia en derechos y decisión política que se cumplan los } \\
\text { dos primeros ítems: tener una ley que reconozca derechos subjetivos, y haber publicado el } \\
\text { catálogo o cartera que los desarrolla. }\end{array}$} \\
\hline & \multicolumn{2}{|c|}{$\begin{array}{l}\text { Pérdida temporal de la excelencia: si durante dos años consecutivos una comunidad } \\
\text { autónoma registra perspectiva negativa y tuviera reconocida la excelencia en este apartado, } \\
\text { la perdería -se vería 'congelada'- hasta que recuperara la perspectiva positiva, por falta de } \\
\text { desarrollo efectivo de los derechos reconocidos y de impulso político. }\end{array}$} \\
\hline
\end{tabular}

* Las cifras negativas indican penalizaciones.

Fuente: Elaboración propia a partir de García et al. (2014).

\begin{tabular}{|l|l|c|}
\hline \multicolumn{2}{|l|}{ Cuadro 2. Indicadores del Índice DEC en el área de relevancia económica (E) } & Puntuación (máx.) \\
\hline Indicador & Descripción & 1,5 \\
\hline Gasto en servicios sociales & $\begin{array}{l}\text { Gasto consolidado de las administraciones públicas en servicios } \\
\text { sociales, por habitante y año }\end{array}$ & 0,8 \\
\hline $\begin{array}{l}\text { Gasto en servicios sociales } \\
\text { (respecto al PIB regional) }\end{array}$ & $\begin{array}{l}\text { Porcentaje de gasto de las administraciones públicas en servicios } \\
\text { sociales, con respecto al PIB regional }\end{array}$ & 0,7 \\
\hline $\begin{array}{l}\text { Gasto en servicios sociales } \\
\text { (respecto al gasto público regional) }\end{array}$ & $\begin{array}{l}\text { Porcentaje de gasto de las administraciones públicas en servicios } \\
\text { sociales, en proporción al gasto total por ellas ejecutado }\end{array}$ & 3,0 \\
\hline Puntuación máxima (total) & \multicolumn{1}{|l|}{$\begin{array}{l}\text { Es condición para alcanzar la excelencia en relevancia económica alcanzar al menos 1,1 } \\
\text { puntos en gasto consolidado en materia de servicios sociales, por habitante y año; y } \\
\text { al menos o,5 puntos en el porcentaje de gasto en servicios sociales con respecto al PIB } \\
\text { regional. }\end{array}$} \\
\hline Excelencia (D mayúscula)
\end{tabular}

Fuente: Elaboración propia a partir de García et al. (2014). 
Cuadro 3. Indicadores del Índice DEC en el área de cobertura (C)

\begin{tabular}{|c|c|c|c|}
\hline \multicolumn{2}{|l|}{ Indicador } & Descripción & Puntuación (máx.) \\
\hline \multicolumn{2}{|l|}{ Estructuras básicas } & $\begin{array}{l}\text { Ratio de trabajadores de plantilla en los centros de servicios sociales } \\
\text { por habitante }\end{array}$ & 0,6 \\
\hline \multirow[t]{3}{*}{ Dependencia } & Cobertura & Porcentaje de beneficiarios del SAAD sobre el total de la población & 0,4 \\
\hline & Limbo & $\begin{array}{l}\text { Porcentaje de personas con dictámenes que dan derecho a } \\
\text { prestación en el SAAD y están pendientes del programa individual de } \\
\text { atención, sobre el total de personas evaluadas con derecho }\end{array}$ & 0,4 \\
\hline & \multicolumn{2}{|c|}{ Puntuación máxima (subtotal) } & 0,8 \\
\hline \multirow[t]{3}{*}{$\begin{array}{l}\text { Rentas mínimas de } \\
\text { inserción }\end{array}$} & Cobertura & $\begin{array}{l}\text { Ratio de perceptores (miembros dependientes) de rentas básicas de } \\
\text { inserción por habitante }\end{array}$ & 0,5 \\
\hline & Cuantía & $\begin{array}{l}\text { Porcentaje que supone el gasto medio por titular de rentas mínimas } \\
\text { de inserción, en relación a la renta media por hogar en la comunidad } \\
\text { autónoma }\end{array}$ & 0,3 \\
\hline & \multicolumn{2}{|c|}{ Puntuación máxima (subtotal) } & 0,8 \\
\hline \multirow{3}{*}{$\begin{array}{l}\text { Plazas residenciales } \\
\text { para personas } \\
\text { mayores }\end{array}$} & Cobertura & $\begin{array}{l}\text { Ratio de plazas en servicios residenciales por cada } 100 \text { personas } \\
\text { mayores de } 65 \text { años }\end{array}$ & 0,4 \\
\hline & $\begin{array}{l}\text { Responsabilidad } \\
\text { pública }\end{array}$ & $\begin{array}{l}\text { Ratio de plazas residenciales públicas por cada } 100 \text { personas } \\
\text { mayores de } 65 \text { años }\end{array}$ & 0,2 \\
\hline & \multicolumn{2}{|c|}{ Puntuación máxima (subtotal) } & 0,6 \\
\hline \multirow[t]{3}{*}{ Ayuda a domicilio } & Cobertura & Porcentaje de cobertura entre personas mayores de 65 años & 0,3 \\
\hline & Intensidad & Intensidad horaria mensual (tareas + cuidados) & 0,3 \\
\hline & \multicolumn{2}{|c|}{ Puntuación máxima (subtotal) } & 0,6 \\
\hline \multicolumn{2}{|l|}{ Infancia } & $\begin{array}{l}\text { Porcentaje de acogimientos familiares sobre el total de acogimientos } \\
\text { a menores }\end{array}$ & 0,4 \\
\hline \multirow[t]{3}{*}{ Discapacidad } & Residencial & $\begin{array}{l}\text { Porcentaje de plazas residenciales para personas con discapacidad } \\
\text { sobre el total de personas con discapacidad }\end{array}$ & 0,2 \\
\hline & $\begin{array}{l}\text { Centros ocupacionales } \\
\text { y centros de día }\end{array}$ & $\begin{array}{l}\text { Porcentaje de plazas en centros ocupacionales y centros de día } \\
\text { sobre el total de personas con discapacidad }\end{array}$ & 0,2 \\
\hline & \multicolumn{2}{|c|}{ Puntuación máxima (subtotal) } & 0,4 \\
\hline \multicolumn{2}{|l|}{ Mujer } & $\begin{array}{l}\text { Ratio de plazas en centros de acogida para mujeres víctimas de } \\
\text { violencia de género, por solicitud de orden de protección a los } \\
\text { juzgados }\end{array}$ & 0,4 \\
\hline \multicolumn{2}{|l|}{ Personas sin hogar } & Ratio de plazas de alojamiento por cada 100.000 habitantes & 0,4 \\
\hline \multicolumn{3}{|c|}{ Puntuación máxima (total) } & 5,0 \\
\hline \multicolumn{2}{|c|}{ Excelencia (C mayúscula) } & \multicolumn{2}{|c|}{$\begin{array}{l}\text { Es condición para alcanzar la excelencia en cobertura de servicios sociales (C mayúscula) } \\
\text { obtener al menos la puntuación media en seis de los nueve aspectos valorados, y obtener } \\
\text { la puntuación máxima en al menos tres. }\end{array}$} \\
\hline
\end{tabular}

Fuente: Elaboración propia a partir de García et al. (2014).

\subsection{Fuentes de datos}

Toda la información que se utiliza para elaborar los indicadores que configuran el Índice DEC proviene de fuentes oficiales y públicas, las cuales vienen señaladas siempre junto al correspondiente dato, con su enlace a la página web de referencia. El uso de fuentes oficiales públicas para elaborar todos los indicadores que configuran el Î́ndice es muy importante para evitar cualquier manipulación o uso interesado de sus resultados. También nos preserva de críticas a los datos que utilizamos, ya que se criticará, en todo caso, la

Siempre que existen, se utilizan fuentes oficiales centralizadas, y sólo en su ausencia se solicita información directamente a las comunidades autónomas. Así, antes de dar por buena la información con la que se construyen los indicadores que configuran el Índice, se remite a cada comunidad autónoma (por correo certificado y por correo electrónico) la que le corresponde, con objeto de que pueda advertir de errores o incorrecciones, y para que pueda aportar información cuando no existan datos centralizados.

\subsection{Aplicación anual y publicación del Î́ndice}

El Índice se aplica anualmente y sus resultados se presentan en un documento que incluye:

- Escala de calificación del desarrollo de los servicios sociales en las diferentes comunidades autónomas, con el correspondiente mapa.

- Informe general sobre su desarrollo en el conjunto del Estado.

- Informe específico sobre cada una de las comunidades, así como detalle de las tablas de cada uno de los indicadores utilizados. 
En 2014, el Índice incorpora un anexo sobre el gasto en servicios sociales que, por primera vez, puede estimar a partir de datos oficiales para cada una de las administraciones (central, autonómica y local), así como su evolución en los últimos años, lo que permite cuantificar los recortes que se han producido tanto en el conjunto del Estado como en cada comunidad autónoma y en cada una de las tres administraciones.

\subsection{Debilidades y retos de la herramienta de medida}

Como decíamos al iniciar este artículo, elaborar un Índice para medir el desarrollo de los servicios sociales es un reto muy complicado, y llevarlo a cabo con medios tan limitados como los que disponemos resulta una verdadera osadía. Vale la pena intentarlo, sin duda, ya que es muy necesario disponer de una herramienta de medida que nos permita monitorizar y valorar el desarrollo del sistema en general y en cada territorio, así como en sus diferentes dimensiones -legislativas, planificadoras, institucionales, económicas y de cobertura en prestaciones y servicios-. Pero conocemos sus limitaciones. Algunas son externas a la propia herramienta de medida, pero condicionan su aplicación y utilidad; otras son debilidades del propio diseño del Î́ndice.

\subsubsection{Limitaciones externas: extraordinarios déficits de información en materia de servicios sociales}

Los contenidos del Índice DEC están condicionados por la mala calidad, el retraso o, lisa y llanamente, por la falta de información oficial en materia de servicios sociales:

- Inexistencia de datos: no existe una sola fuente oficial de datos de cobertura de servicios sociales sobre materias tan importantes como la atención a las personas con discapacidad (número de plazas residenciales, en centros de día u ocupacionales). Tampoco se puede saber por medio de ninguna fuente oficial cuántas plazas de acogida hay para mujeres víctimas de violencia de género.

- Falta de actualidad de la información: algunos datos que el Ministerio de Sanidad, Servicios Sociales e Igualdad ofrece como actuales corresponden, en realidad, a 2011, como los referidos a las residencias de personas mayores, el servicio de ayuda a domicilio o a las estadísticas del Plan Concertado. ¿Hay algo que justifique este retraso? Especialmente en un asunto en el que existen compromisos de información por parte de las comunidades autónomas, vinculados a los compromisos de financiación por parte del Ministerio, ¿por qué no se exige el cumplimiento de esos compromisos como requisito para recibir la financiación comprometida? Y si la información es facilitada de manera puntual por las comunidades autónomas, ¿por qué no se hace pública?
- Baja calidad de la información. La falta de definición de determinadas variables hace que la información oficial no tenga la calidad requerida, especialmente en cuanto a su homogeneidad entre unas y otras comunidades, 0 , incluso dentro de una misma comunidad, entre varias localidades o territorios. A ello se une la desidia a la hora de registrar y aportar información, que hace que con frecuencia asistamos a un esperpéntico espectáculo cuando algunos responsables institucionales del Ministerio o de alguna comunidad autónoma descalifican los análisis o resultados del DEC diciendo que "los datos no son ciertos", ¡unos datos que ellos mismos han aportado y publicado de forma oficial! Hasta se da el caso de que el Ministerio publique simultáneamente diferentes estadísticas de un mismo servicio (por ejemplo, la ayuda a domicilio), con resultados muy diferentes en unas y otras...

Incluso en los indicadores económicos, que tienen una referencia clara para todas las administraciones en el conjunto del Estado (por ejemplo, el ya mencionado 'funcional 23') también sospechamos que pueden existir desajustes a la hora de llevar a cabo de manera homogénea la contabilidad en diferentes entidades locales o comunidades autónomas, de manera que un mismo concepto de gasto pueda ser contabilizado en el grupo de función 23 en una de estas entidades, y en otra, no.

Se trata de limitaciones atribuibles a la baja calidad de la información, que no podemos sino señalar, pero que no está en nuestra mano corregir. En todo caso, constituyen una de las principales debilidades del Îndice DEC, que hacen inviable elaborar determinados indicadores, por falta de información, y provocan que sus resultados sean menos precisos y no reflejen, en algunos casos, la realidad.

Todos estos déficits de la información en materia de servicios sociales suponen una quiebra del derecho de los ciudadanos a la información, una falta de cumplimiento por parte del Ministerio de sus responsabilidades en esta materia, y un gravísimo problema para valorar o planificar racionalmente el desarrollo de los servicios sociales.

\subsubsection{Debilidades internas del Índice}

Somos conscientes, cuando menos, de las siguientes debilidades:

- Falta de referencias ‘ancladas’. El sistema de servicios sociales carece de referencias. El Índice DEC, también. La única referencia para valorar el desarrollo de un determinado indicador de gasto o cobertura es la correspondiente media estatal. Así, se califica a cada comunidad autónoma en relación con la media estatal, en una escala que otorga mayor puntuación a las que están por encima -mejor- que la media, y menos a las que están por debajo - peor-. Así, puede ocurrir que una comunidad 'mejore' de uno a otro ejercicio en un 
determinado indicador, obteniendo una mayor puntuación que en el año anterior, no porque haya registrado una mejora real, sino porque en el conjunto del Estado se haya producido un descenso mayor. Queda como reto para próximas aplicaciones del Índice (tenemos el compromiso de hacerlo para la de 2015) señalar referencias 'ancladas' para los indicadores de gasto y de cobertura, que permitan constatar una evolución real y no sólo relativa (en comparación con la media estatal) de cada uno de ellos. Será preciso revisar periódicamente -quizás cada cinco años- estas referencias, ya que lo que en un determinado momento puede ser un nivel de desarrollo óptimo, puede que más adelante no lo sea. Por ejemplo, quizás es necesario revisar la referencia de la necesidad de seis plazas residenciales por cada cien personas mayores de 65 años, ya que tanto el límite de edad como la percepción y la demanda de plazas residenciales ha variado sustancialmente. Una vez 'ancladas' las referencias, sobrepasarlas por encima de un determinado nivel no debe ser más valorado en el Índice, ya que puede suponer un gasto o una oferta de servicios sobredimensionados, innecesarios y, como tal, antieconómicos y disfuncionales para el sistema.

- Indefinición o imprecisión de ciertos indicadores. Algunos de los indicadores del Índice necesitan mayor concreción, de manera que resulten inequívocos, especialmente en aquellos en los que no existe fuente de información oficial centralizada y hay que solicitar los datos directamente a las comunidades autónomas. Es el caso de servicios para personas con discapacidad, donde hemos constatado que, en la información remitida por algunas comunidades, se incluyen conceptos que otras no incluyen (por ejemplo, las personas con enfermedad mental). De la misma manera, será necesario precisar muy bien los conceptos de gasto que se incluyen en el sistema, ya que algunos tan significativos como el gasto en rentas mínimas de inserción se contabilizan fuera del 'funcional 23' en algunas comunidades, como es bien sabido.

- Ausencia de ciertos indicadores y ajuste de la ponderación de alguno de ellos. Ya hemos dicho cómo hemos ido incorporando algún nuevo indicador al Índice en anteriores aplicaciones, lo que nos obliga a reformular la ponderación del resto para mantener la escala de 10 puntos. Para 2015, tenemos el compromiso de incorporar los centros de día para personas mayores y la teleasistencia, lo que nos obligará a una nueva reformulación, ya planteada, incrementando el peso de la cobertura, en detrimento del área de derechos y decisión política. Es fácil que, en futuras aplicaciones, y siempre que exista información para ello, podamos precisar, con nuevos indicadores, los servicios sociales para la infancia, para las mujeres o para las personas sin hogar, que hoy son muy limitados.

Subsanar estas deficiencias es un reto que nos planteamos para mejorar y adaptar permanentemente la herramienta de medida que es el Índice DEC. En todo caso, y esto es muy importante, para evitar manipulaciones en sus resultados - no deja de haber presiones interesadas en ello...-, cualquier modificación que se incluya en la herramienta (nuevo indicador, reformulación de un indicador, cambios en la ponderación) requiere ser advertida desde la anterior aplicación; sólo así es posible evitar modificaciones interesadas, hechas a última hora para conseguir determinados resultados.

\section{La aplicación del Î́ndice DEC en $2014^{3}$}

\subsection{Procedencia y actualidad de los datos}

Las fuentes utilizadas para elaborar los indicadores en la aplicación del Índice DEC en 2014 tienen la siguiente procedencia:

- Los que se construyen a partir de información oficial centralizada suponen 7,2 puntos sobre los 10 que conforman la puntuación total del Índice.

- Dos puntos de los diez se obtienen directamente de información que existe a nivel autonómico. Son los correspondientes al apartado $D$ (derechos y decisión política).

- Sólo o,8 de los 10 puntos del Índice corresponden a indicadores cuya información se solicita directamente a las comunidades autónomas, en ausencia de información oficial centralizada: los referidos a plazas residenciales y centros de día para personas con discapacidad, y plazas en centros de acogida para mujeres víctimas de violencia de género.

Trece de las diecisiete comunidades autónomas aportaron información sobre estos aspectos. Las que no aportan datos no puntúan en dichos indicadores. A Euskadi y Navarra se les solicita también información sobre los puestos de trabajo en plantilla en las estructuras básicas de servicios sociales, ya que esta información no se recoge en las estadísticas del Plan Concertado.

Respecto a la actualidad de la información, cabe señalar que:

- El $66 \%$ de la ponderación del Índice (6,6 de sus 10 puntos) se otorga a partir de información correspondiente a 2013. Es el caso de todos los indicadores de los apartados $\mathrm{D}$ (derechos y decisión política) y E (relevancia económica), así como de los indicadores de cobertura en materia de dependencia (C.2), plazas residenciales y centros de día para personas con discapacidad (C.7) y plazas en centros acogida para mujeres víctimas de violencia de género (C.8).

- El $28 \%$ corresponde a 2012 (2,8 de sus 10 puntos). Es el caso de los indicadores de cobertura en materia de rentas mínimas de inserción (C.3), plazas residenciales para personas mayores de

\footnotetext{
3 Para más detalles, puede consultarse García et al. (2014).
} 
65 años (C.4), ayuda a domicilio para este mismo grupo (C.5), acogimiento de menores (C.6) y plazas residenciales para personas sin hogar (C.9).

- El 6\% restante corresponde a 2011 (1 de sus 10 puntos). El único indicador con una antigüedad de más de dos años es el de plantilla de los centros de servicios sociales, albergues y centros de acogida (C.1).

En consecuencia, el Îndice mide, en sus líneas generales, la situación de los servicios sociales en el año anterior al que se realiza la aplicación, en este caso, en 2013, y sólo una tercera parte de su puntuación se elabora con indicadores construidos con información anterior a ese año, si bien en muchos de estos aspectos no es previsible que se produzcan variaciones significativas de un año a otro, por su carácter estructural (cobertura de plazas en centros, fundamentalmente).

\subsection{Resultados}

La conclusión más destacable que resulta de la aplicación del Índice DEC en 2014 es que los servicios sociales en España están en un acusado proceso de deterioro, que expresa el vaciamiento del derecho a los servicios sociales. Esto ocurre precisamente cuando son más necesarios, ante la crítica situación que viven cientos de miles de personas y familias empobrecidas, y por el riesgo de que se produzca el demoledor paso de la pobreza a la exclusión social para muchas de ellas, riesgo que los servicios sociales deben y pueden impedir o minimizar.

\subsubsection{Un recorte de 2.212 millones de euros anuales}

En 2014 el Índice DEC analiza, por primera vez, el gasto en servicios sociales del conjunto de las administraciones públicas en cada territorio, y no sólo el de sus Gobiernos autonómicos. Un análisis que se ha retrotraído al año 2011 para apreciar, con datos homogéneos, la evolución de este gasto. Los resultados son demoledores (Gráfico 1). En los tres últimos años, el gasto anual por habitante en servicios sociales ha pasado, en el conjunto del Estado, de 354,02 $€$ a 306,91 $€$, es decir, 47,11 € menos por habitante y año, lo que representa una reducción del $13,3 \%$. En términos absolutos, las comunidades autónomas y las entidades locales han gastado $\mathbf{2 . 2 1 2}$ millones de euros menos en servicios sociales en 2013 en relación con lo que gastaron en 2011. Éste es el impacto de los recortes en servicios sociales.

Todas las comunidades autónomas, excepto La Rioja, han reducido en términos absolutos (euros por habitante y año) su gasto en servicios sociales entre 2011 y 2013. Sin embargo, varias de ellas han visto incrementar el gasto de sus administraciones públicas en servicios sociales en 2013 en relación con el año anterior. El caso más espectacular se registra en Euskadi, con $390,75 €$ menos por habitante y año en 2013 que en 2011 (-41,9\%). La explicación es que, en esta comuni-

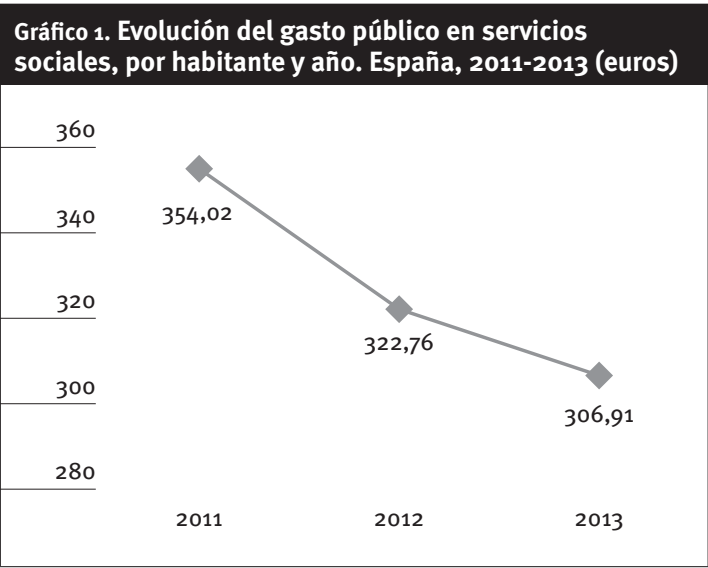

Fuente: García et al. (2014).

dad, ha dejado de computarse en servicios sociales el gasto de sus rentas mínimas de inserción, que han pasado a ser gestionadas por el Departamento de Empleo. A pesar de ello, el gasto en servicios sociales de las administraciones públicas en Euskadi sigue siendo el más importante de todas las comunidades y muy superior a la media del conjunto del Estado. Otras comunidades han reducido su gasto en servicios sociales, en términos absolutos (euros por habitante y año) y relativos, muy por encima de la media estatal, sin que exista una justificación, como en el caso de Euskadi: Castilla-La Mancha (-144,84€, -28,18\%), Navarra (-124,0€, -23,16\%), Murcia (-47,16€, -17,6\%) y Extremadura $(-68,41 €,-15,36 \%)$.

Esta reducción no es consecuencia de un empobrecimiento de la sociedad española, sino fruto de una menor capacidad -o interés- de las Administraciones Públicas de recaudar y redistribuir la riqueza a través de políticas sociales dirigidas a las personas y familias más necesitadas. Así lo pone de manifiesto que el porcentaje del PIB que se dedica a servicios sociales se haya reducido en 0,19 puntos en los tres últimos años (de 1,60\% en 2011 a 1,41 \% en 2013) [Gráfico 2] y que el porcentaje del gasto que las Administraciones Públicas dedican a servicios sociales sobre el total del gasto público se haya reducido, asimismo, en 0,4 puntos (del 8,14\% en 2011 al 7,74\% en 2013).

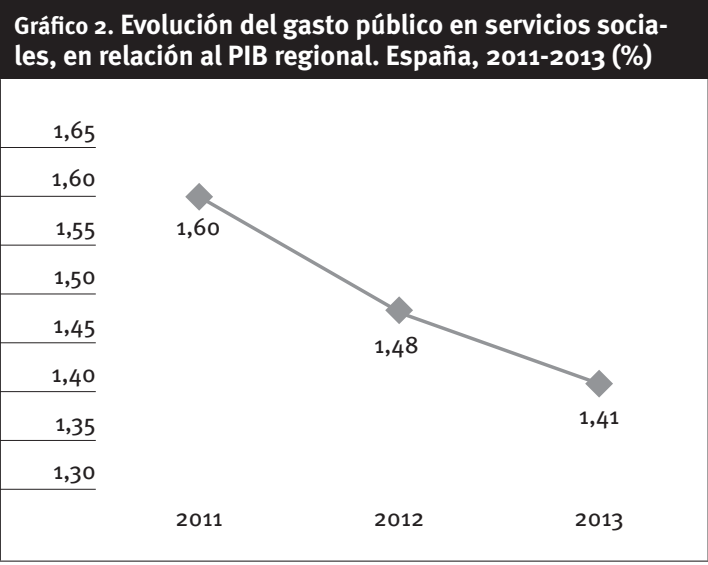

Fuente: García et al. (2014). 


\subsubsection{El recorte en el gasto en servicios sociales es el doble en las entidades locales que en los Gobiernos autonómicos}

Mientras que los Gobiernos autonómicos han recortado, como media, un $10,5 \%$ su gasto en servicios sociales en 2013 respecto a 2011, el recorte ha sido casi el doble, un $20,8 \%$ en las entidades locales (tomando como referencia su esfuerzo propio, es decir, descontando las trasferencias que reciben de su comunidad autónoma) [Gráfico 3]. Este mayor recorte del gasto en servicios sociales en las entidades locales evidencia las dificultades presupuestarias que atraviesan, pero sobre todo pone de manifiesto que el mayor deterioro de los servicios sociales se está produciendo, en especial, en los servicios básicos y de proximidad, que gestionan las entidades locales y que constituyen el elemento de coherencia e integración el sistema, y una de sus principales fortalezas. La preocupación es mayor, ya que los servicios sociales en el ámbito local están amenazados por la Ley de Racionalización y Sostenibilidad de la Administración Local, cuyos efectos se están empezando a notar en 2014 y pueden ser aún más acusados en los dos próximos años. La verdadera demolición del sistema de servicios sociales se está produciendo, sin duda, en su nivel más estratégico, en los servicios sociales básicos y de proximidad.

告

Gráfico 3. Evolución del gasto público de comunidades autónomas y entidades locales en servicios sociales. España, 2011-2013 (millones de euros)

15.000

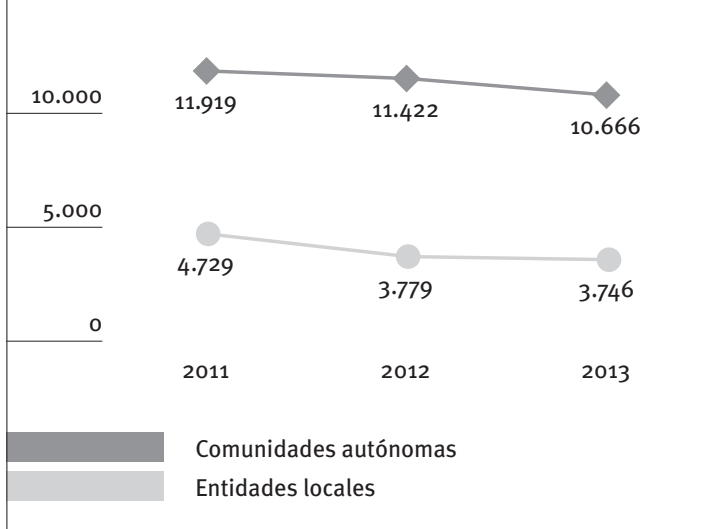

Fuente: García et al. (2014).

\subsubsection{El retroceso en la oferta de servicios y prestaciones}

La reducción del gasto en $\mathbf{2 . 2 1 2}$ millones de euros anuales en los tres últimos años tendrá, sin duda, un reflejo significativo en los servicios y prestaciones del sistema. Resulta imposible poner cifras a esta reducción, ya que no existe información actualizada en muchos de los indicadores de cobertura. Así ocurre con servicios y prestaciones tan significativos como las rentas mínimas de inserción, o los servicios residenciales y domiciliarios para personas mayores, de los que la última información oficial disponible corresponde a 2012; en el caso de la red básica, los últimos datos oficiales publicados son de $2011 . .$.

Puede darnos una idea de cómo la reducción del gasto afecta a la oferta de servicios y prestaciones el Sistema para la Autonomía y la Atención a la Dependencia, del que disponemos de datos actualizados, y la serie que permite apreciar su evolución ininterrumpida desde 2007 (Barriga et al., 2014). Pues bien, estos datos permiten constatar un deterioro del sistema, cuya expresión más nítida es la contención en el número de beneficiarios, a partir de julio de 2012, y la caída, por primera vez desde que se implanta el sistema, en el presente año (Gráfico 4) ${ }^{4}$.

¿Cómo afecta esta reducción del número de beneficiarios del sistema a los servicios y prestaciones que ofrece? Desde junio de 2013 a mayo de 2014, la reducción más importante es el descenso de prestaciones económicas de cuidados en el entorno familiar (PECEF); pero en lo que a servicios se refiere, la reducción se deja sentir especialmente en el servicio de ayuda a domicilio y la teleasistencia, con 6.380 y 7.467 servicios menos, respectivamente, en sólo un año (Gráfico 5). El deterioro de los servicios domiciliarios ya se anunciaba en los datos correspondientes a 2011, los últimos oficiales publicados sobre el porcentaje de personas mayores de 65 años que recibían el servicio de ayuda a domicilio: ese porcentaje se redujo en 0,29 puntos respecto al año anterior (Gráfico 6).

Tampoco se constata ningún servicio que incremente su cobertura en los últimos años; ni siquiera una prestación tan necesaria en estos momentos como las rentas mínimas de inserción registran el incremento que cabría esperar, como pone de manifiesto el último dato oficial conocido, en este caso, correspondiente a 2012 (Gráfico 7).

Sería muy importante que el Ministerio ofreciera datos actualizados de estos servicios y del resto, para constatar si se confirman las tendencias apuntadas.

\subsubsection{El fraude de las nuevas leyes de servicios sociales}

Otro aspecto desalentador en la trayectoria del sistema de servicios sociales es constatar que en los dos últimos años (2013 y 2014) no se ha aprobado ninguna nueva ley de servicios sociales, ni tampoco ningún catálogo, mapa o plan estratégico. Por el contrario, algunos mapas o planes han perdido su vigencia sin ser reeditados. Sólo se tiene constancia de una comunidad que ha aprobado, en 2014, un proyecto de ley de nueva generación (Andalucía) y de otras dos que

4 El número de personas atendidas sigue reduciéndose de manera significativa después de julio de 2014, fecha del último dictamen del Observatorio Estatal de la Dependencia (Barriga et al., 2014). 
Gráfico 4. Evolución del número de personas atendidas por el Sistema para la Autonomía y la Atención a la Dependencia.

España, 2009-2014 (miles de personas)

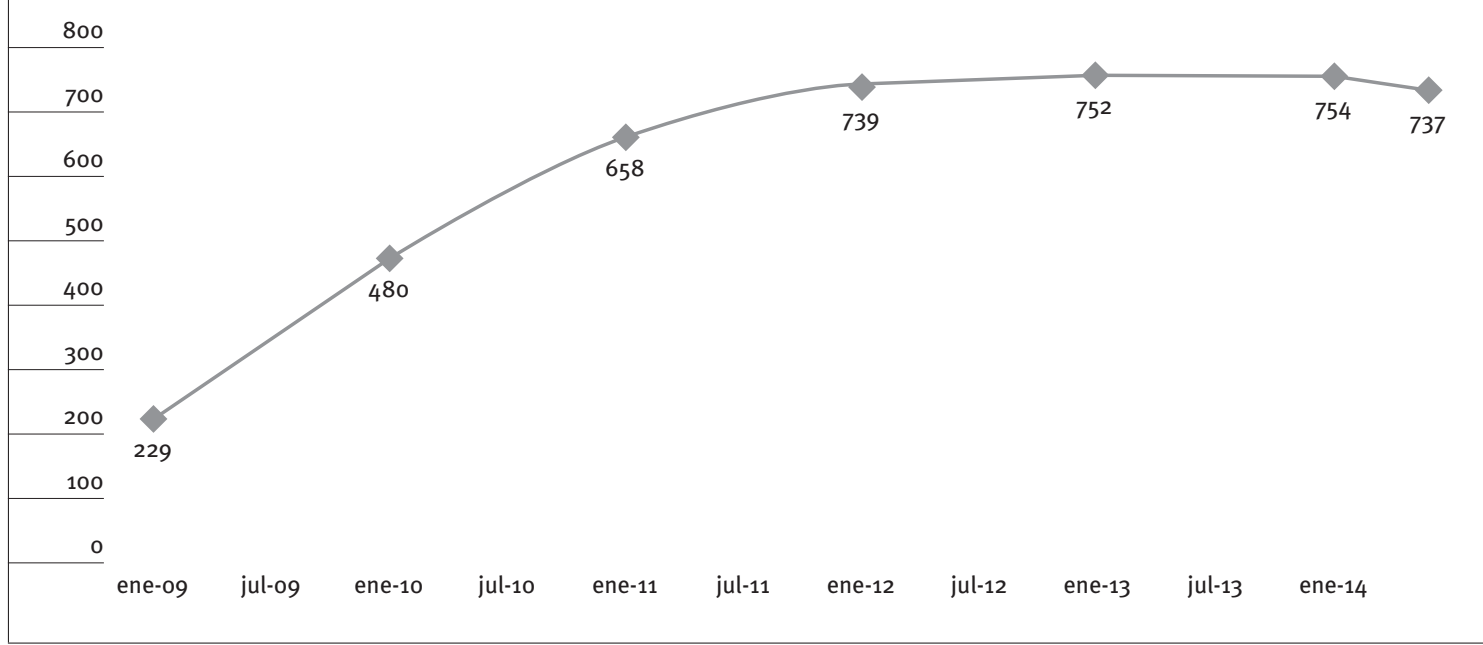

Fuente: Barriga et al. (2014).

Gráfico 5. Evolución del número de prestaciones y servicios entregados por el Sistema para la Autonomía y la Atención a la Dependencia, por tipo de recurso. España, junio 2013 - mayo $2014(\% \Delta)$

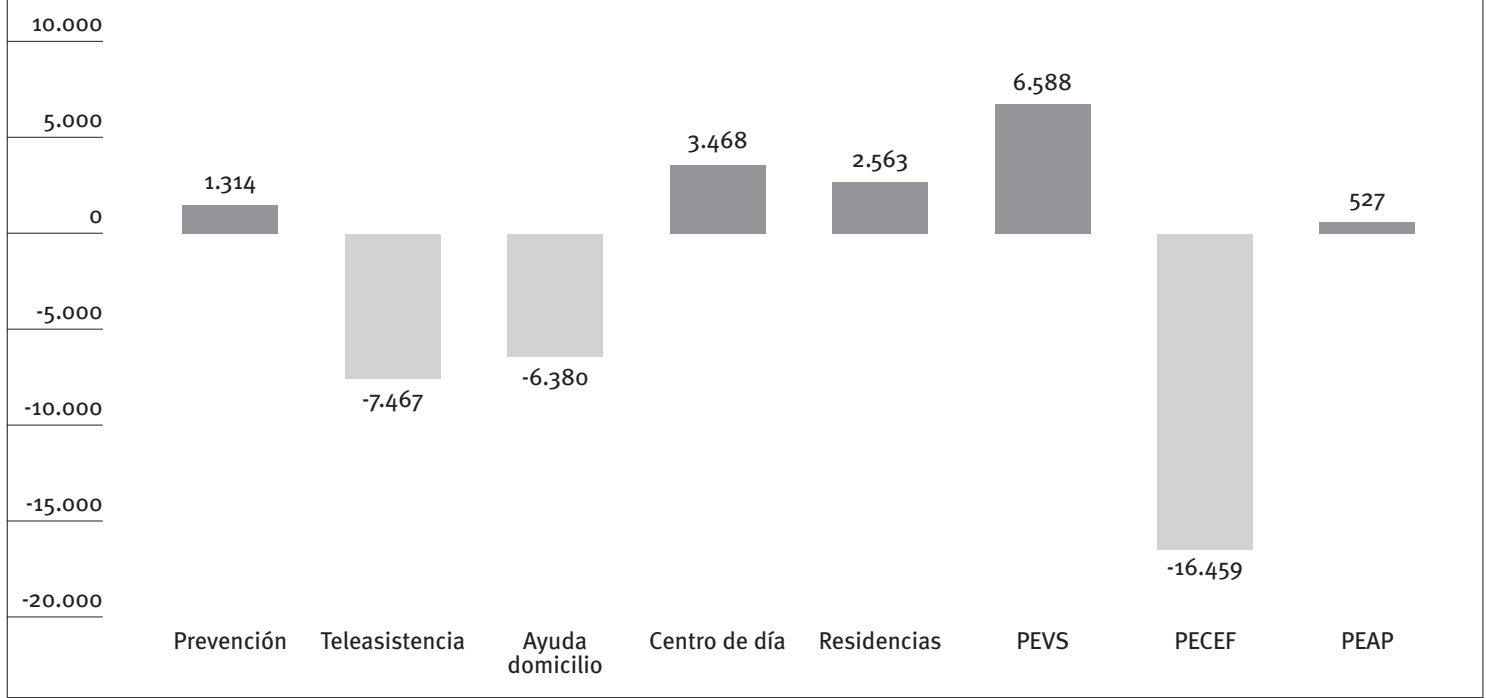

PEVS: prestación económica vinculada al servicio. PECEF: prestación económica para cuidados en el entorno familiar y apoyo a cuidadores no profesionales. PEAP: prestación económica de asistencia personal.

Fuente: Barriga et al. (2014).

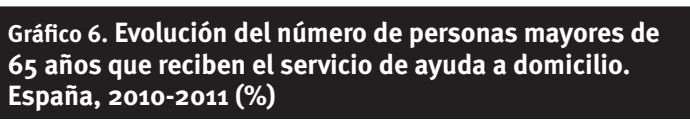

España, 2010-2011 (\%)

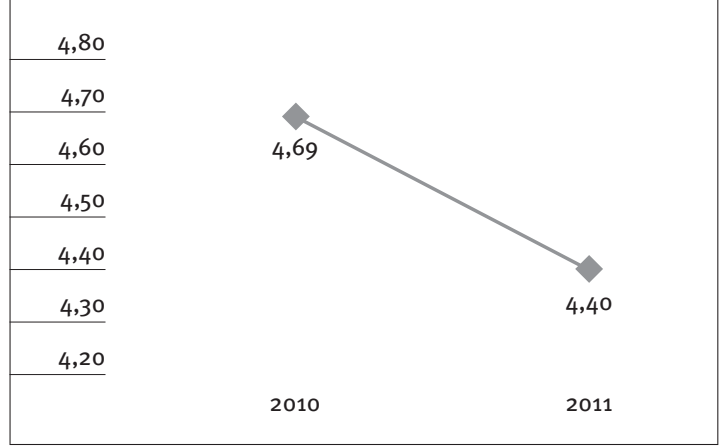

Fuente: García et al. (2014).
Gráfico 7. Evolución de la ratio de perceptores/as de rentas mínimas de inserción por habitante. España, 2010-2012

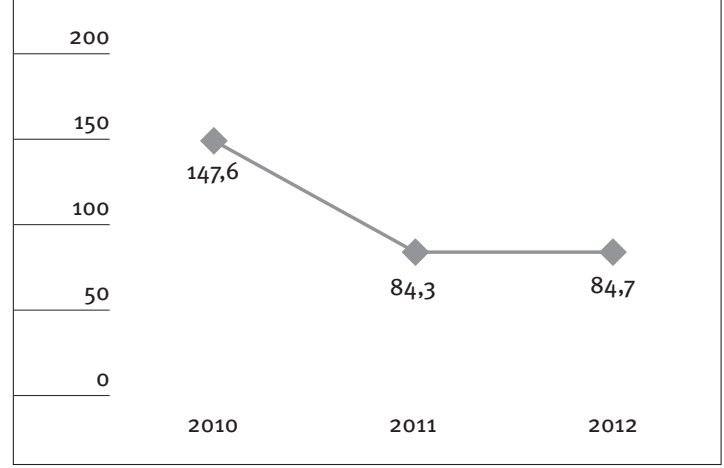

Fuente: García et al. (2014). 
tienen avanzado el proceso de elaboración y aprobación de su plan estratégico (Euskadi y Castilla y León).

Pero lo más preocupante es constatar que, en las comunidades autónomas que aprobaron leyes 'de nueva generación', que garantizaban derechos subjetivos y establecían herramientas para su concreción normativa ('catálogos'), no sólo no han tenido los efectos que cabría esperar, sino que se han registrado alguno de los mayores retrocesos en sus servicios sociales, tanto en inversión como en cobertura efectiva de servicios y prestaciones. Es evidente que están incumpliendo de manera flagrante las leyes, los catálogos y los planes que tantas expectativas generaron, y vaciando de contenido esa referencia tan esperada del derecho subjetivo a los servicios sociales.

Hemos llamado la atención reiteradamente sobre el carácter antisistema de estas prácticas: ¿cómo puede un Gobierno exigir a sus ciudadanos/as que cumplan las leyes si los propios Gobiernos las incumplen cuando les conviene?, ¿cómo pedir confianza en las instituciones cuando éstas utilizan toda su maraña de procedimientos para dificultar, o impedir en la práctica, que los/as ciudadanos/as reclamen sus derechos subjetivos a los servicios sociales cuando éstos se ven vulnerados? La demolición de los servicios sociales no sólo perjudica la calidad de vida de las personas y de las familias, la cohesión social y el empleo, sino que es un ataque a la esencia del Estado de Derecho, basado en el cumplimiento de las leyes, y en el que los gobernantes deben dar ejemplo de ello; y también una pérdida absoluta de confianza en sus instituciones.

\subsubsection{Un nivel de desarrollo débil: los riesgos de que la pobreza dé paso a la exclusión social}

En 2014, sólo una comunidad autónoma alcanza un nivel de desarrollo 'medio alto' de sus servicios sociales (Euskadi); y otra, un nivel 'medio' (Castilla y León). Siete alcanzan un nivel 'medio bajo': Navarra, La Rioja, Asturias, Cataluña, Cantabria y Castilla-La Mancha. Tres obtienen una calificación de 'débil': Aragón, Extremadura y Baleares. El desarrollo de los servicios sociales en las seis restantes se califica de 'irrelevante’: Andalucía, Madrid, Galicia, Murcia, Canarias y Valencia.

El pasado año ya pusimos de manifiesto la capacidad de contención de los servicios sociales, al relacionar su nivel de desarrollo según el Índice DEC, con los datos de pobreza-exclusión social en cada comunidad autónoma que aportaba el análisis del Instituto Valenciano de Investigaciones Económicas (Herrero, Soler y Villar, 2013) expresado en términos de Índice de Pobreza Humana (IPH2). La actualización de los datos de dicho índice sintético presentada recientemente (Instituto Valenciano de Investigaciones Económicas, 2014) aporta la tasa de variación del IPH2 entre 2007 y 2012 por comunidades autónomas, lo que sería un reflejo de las necesidades de actuación del sistema de servicios sociales. Lo sorprendente es que, salvo algunas excepciones, la presión de la demanda (mayores necesidades de la población) se corresponde en demasiadas ocasiones con territorios en los que el sistema de servicios sociales tiene un desarrollo deficitario (Gráfico 8).

Gráfico 8. Evolución del Îndice DEC y del Îndice de Pobreza Humana. España, 2007-2012

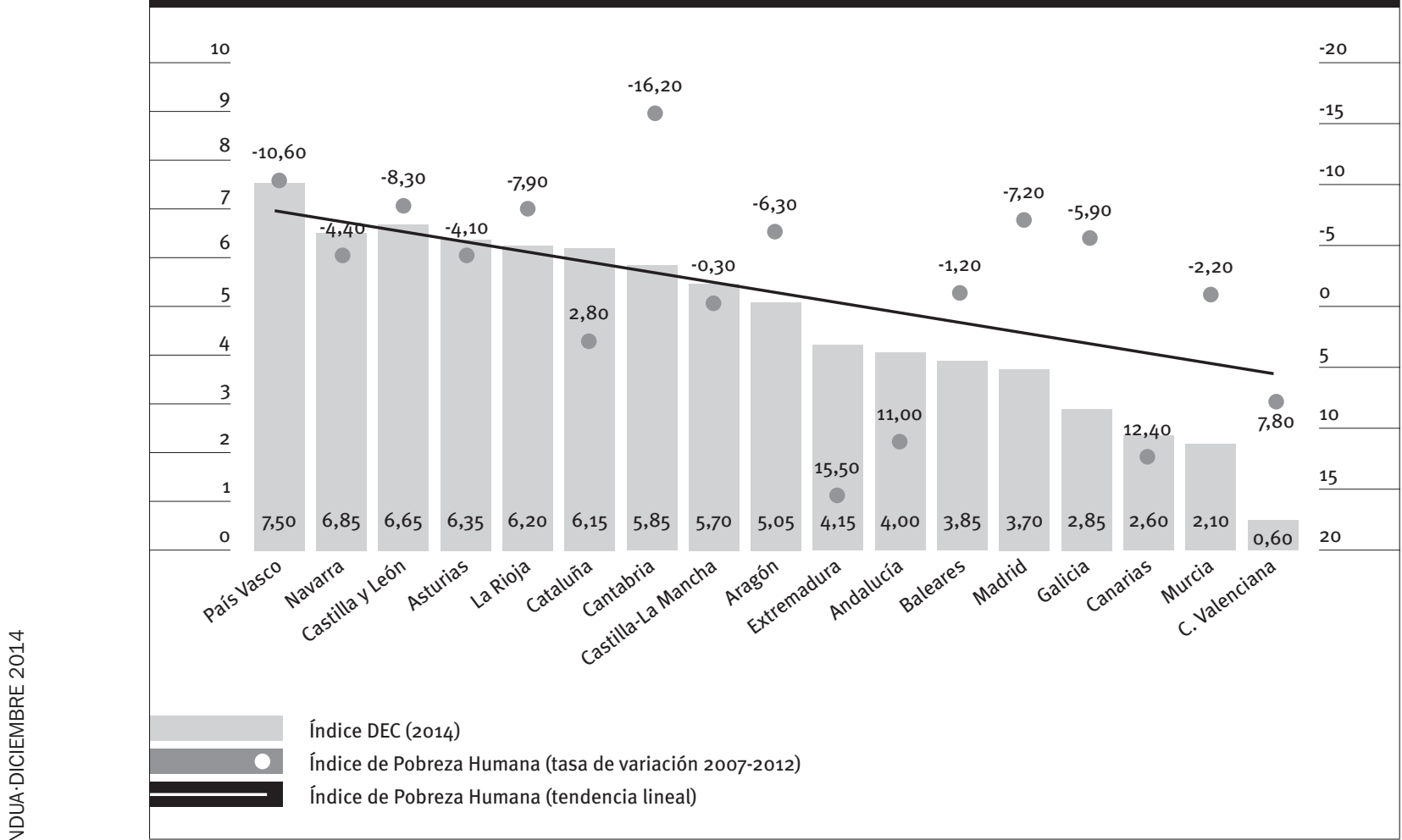

Fuente: Elaboración propia a partir de Herrero, Soler y Villar (2013). 
Resulta preocupante que, en algunos territorios en los que el empobrecimiento en términos de IPH se ha incrementado sensiblemente en el intervalo 20072012 (Extremadura, Canarias, Andalucía o Valencia), el sistema el sistema de servicios sociales presente bajos niveles de desarrollo. No pueden afrontar con suficiencia la creciente demanda y, de hecho, los niveles de pobreza crecen de manera alarmante, si bien hay que considerar que el comportamiento del factor empleo es crucial.

En el otro extremo, encontraríamos comunidades como el País Vasco, Castilla y León, La Rioja o Cantabria, con buenas puntuaciones en el índice DEC y que habrían rebajado sus Índices de Pobreza Humana en el transcurso de la crisis. A estas comunidades se añadirían otras en las que, si bien el índice DEC denota un sistema de servicios sociales con bajo desarrollo, otros factores, como bajas tasas de desempleo 0 la baja tasa de población activa (que afecta a la de pobreza, por la existencia de gran número de perceptores de pensiones) hacen que también se haya mejorado el IPH. Tal es el caso de Madrid o de Galicia.

\subsubsection{Extraordinaria disparidad entre comunidad autónomas}

La primera aplicación del Índice DEC (2012) puso cifras a lo que era una evidencia: la extraordinaria diversidad de esfuerzos, cobertura y derechos garantizados. La segunda y tercera aplicaciones del Índice (2013 y 2014) confirman que tales diferencias no sólo no se han reducido, sino que, en buena parte de los indicadores, continúan aumentando:

- Un trabajador de plantilla en los servicios sociales básicos municipales por cada 720 habitantes en una comunidad (Navarra); en la Comunidad de Madrid, uno por cada 7.916.

- El 2,50\% de la población recibe atenciones del Sistema para la Autonomía y la Atención a la Dependencia en La Rioja; en Canarias, el 0,54\%.

- Sólo un 1,7\% de personas a quienes se ha reconocido el derecho a recibir atenciones del Sistema para la Autonomía y la Atención a la Dependencia están a la espera de recibirlas en Castilla y León, iy un $52,7 \%$ en Canarias!

- Una de cada 16,9 personas residentes en el País Vasco se beneficia de las rentas mínimas de inserción en esa comunidad, mientras que en CastillaLa Mancha es sólo una de cada 355.

- La cuantía que percibe un beneficiario de estas rentas mínimas de inserción en Cataluña supone el $21,8 \%$ de la renta media por hogar en esa comunidad, y sólo un $5,35 \%$ en la Comunidad Valenciana.

- En Castilla y León, hay 7,23 plazas residenciales por cada 100 personas mayores de 65 años; en Murcia, sólo 2,29.

- En Extremadura, hay 2,93 plazas residenciales públicas por cada 100 personas mayores de 65 años; en Murcia, sólo 0,52.
- En la Comunidad de Madrid, el servicio de ayuda a domicilio alcanza al 7,31\% de las personas mayores de 65 años; en el País Vasco, sólo al 1,9\%.

- La media de horas semanales del servicio de ayuda a domicilio es de 35,86 en Andalucía; y sólo de 6,39 en Navarra.

- El 79,01\% de los acogimientos a menores en Murcia son de carácter familiar; en Navarra, sólo el 38,09\%.

- En el País Vasco, hay una plaza de acogida por cada 1,28 mujeres víctimas de violencia de género con orden de protección; en Murcia, una por cada 20,39.

- En el País Vasco, hay 127,76 plazas de alojamiento para personas sin hogar por cada 100.000 habitantes; en Extremadura, 17,48.

Estas grandes diferencias tienen su origen en una extrema disparidad en el gasto en servicios sociales que realizan las Administraciones Públicas en cada territorio:

- En 2013, el País Vasco gastó en servicios sociales $541,24 €$ por habitante y año, frente a los 196,13 de la Comunidad Valenciana.

- El gasto que realizaron la comunidad autónoma y las entidades locales extremeñas en materia de servicios sociales representó en 2013 un 2,57\% de su PIB regional, mientras que en la Comunidad de Madrid fue sólo de un 0,93\%.

- El gasto en servicios sociales en la comunidad autónoma y en las entidades locales de Castilla-La Mancha en 2013 supuso un 9,67\% del total del gasto de estas administraciones. En la Comunidad Valenciana, sólo un $5,89 \%$.

Además, es también significativa la diferencia entre unos y otros territorios en cuanto al esfuerzo económico que realizan las diferentes administraciones en materia de servicios sociales:

- En 2013, el del Gobierno de Cantabria representaba el 92,1\% del total del gasto de las administraciones en materia de servicios sociales en esa comunidad; y las entidades locales, el 7,9\%. En la Comunidad Valenciana, el de su Gobierno representaba sólo el 71,1\% del gasto de las administraciones en servicios sociales; y el de las entidades locales, el 28,9\%.

- El Gobierno de Asturias financiaba el 47,5\% del gasto de las entidades locales en servicios sociales. El Gobierno de Aragón, sólo el 8,05\%.

En el aspecto económico, las diferencias entre territorios, aun siendo importantes, no se van incrementando, sino que se reducen, como consecuencia de que algunas de las comunidades con mayor gasto en servicios sociales han sido las que más lo han reducido en los dos últimos años. Lo vemos en los Gráficos 9 a 12, en los que comparamos la evolución de cada uno de estos indicadores en las dos 
Gráfico 9. Evolución del gasto público en servicios

sociales, por habitante y año. Navarra y Comunidad Valenciana, 2011-2013 (euros)

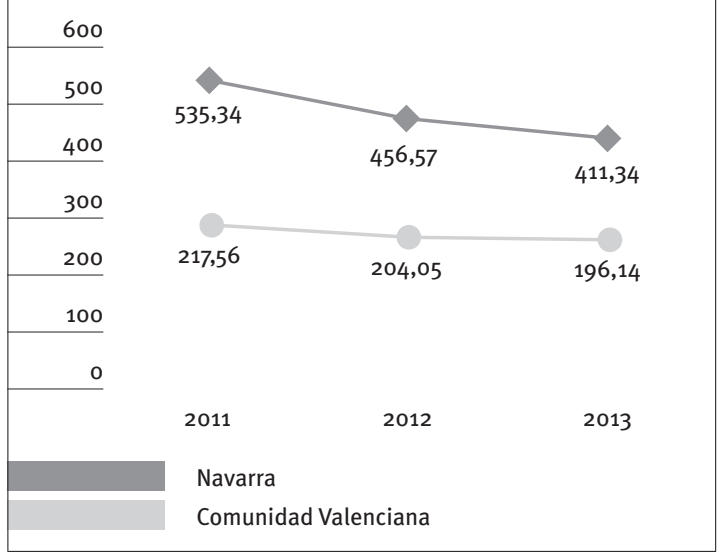

Fuente: Elaboración propia a partir de García et al. (2014).

Gráfico 11. Evolución del gasto público en servicios sociales de comunidades autónomas y entidades locales, en relación al gasto público total de esas administraciones. Castilla-La Mancha y Comunidad Valenciana, 2011-2013 (\%)

in

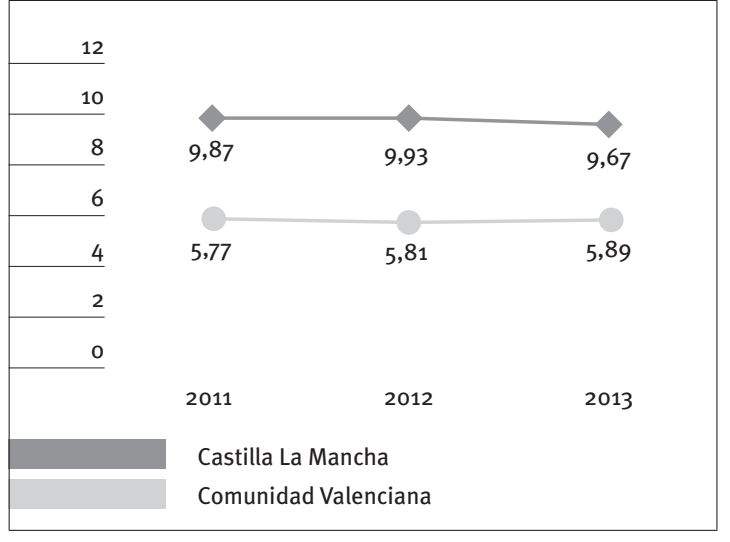

Fuente: Elaboración propia a partir de García et al. (2014).

comunidades que presentan valores más extremos, obviando el peculiar caso de Euskadi, por el efecto ya comentado de la salida del gasto de sus rentas mínimas de inserción del presupuesto de Servicios Sociales.

\subsubsection{Se confirma que el desarrollo de los servicios sociales es resultado de formas de organización y gestión eficientes y no sólo de un mayor gasto: la descentralización y el protagonismo local son determinantes para la eficacia y eficiencia del sistema}

La aplicación del Índice DEC en 2014 confirma que el éxito en el desarrollo de los servicios sociales no sólo tiene que ver con el mayor o menor esfuerzo económico que realizan las administraciones. No necesariamente las comunidades con mayor gasto en servicios sociales (tanto autonómico como local) son
Gráfico 10. Evolución del gasto público en servicios

sociales de comunidades autónomas y entidades locales, en relación al PIB regional. Extremadura y Comunidad de Madrid, 2011-2013 (\%)

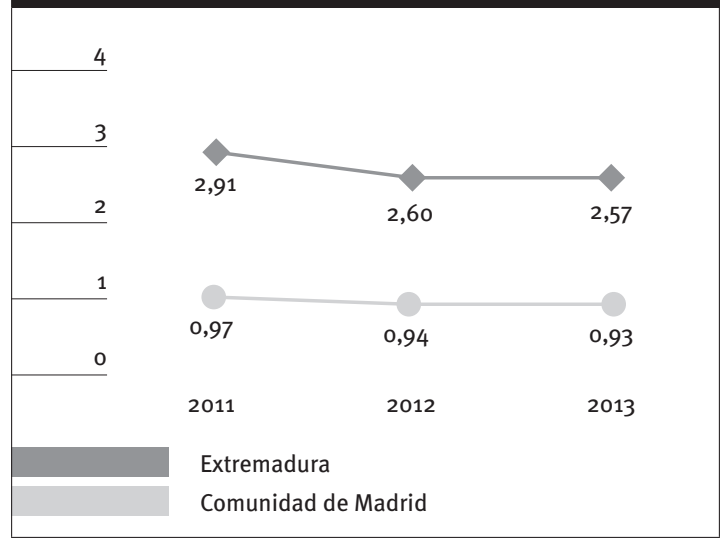

Fuente: Elaboración propia a partir de García et al. (2014).

Gráfico 12. Evolución del gasto público en servicios sociales del Gobierno autonómico, en relación al gasto público total de esa misma comunidad autónoma y de sus entidades locales. Cantabria y Comunidad Valenciana, 2011-2013 (\%)

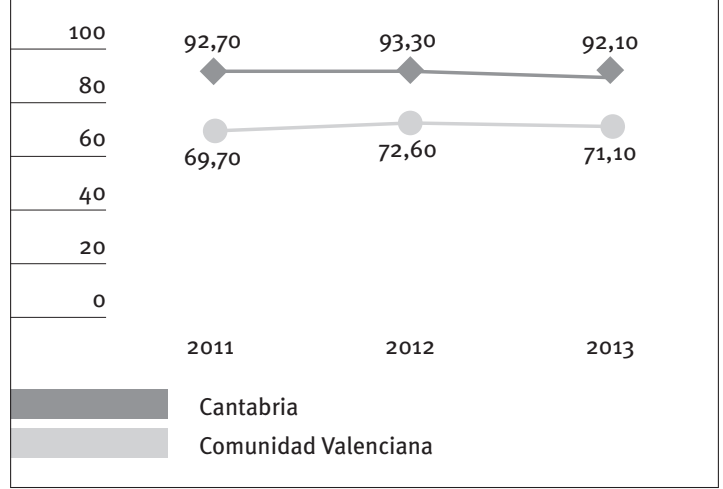

Fuente: Elaboración propia a partir de García et al. (2014).

las que tienen mejor cobertura, es decir, mayor oferta de prestaciones y servicios: Extremadura y Castilla-La Mancha, las comunidades que mayor porcentaje de su PIB regional dedican a servicios sociales (2,57\% y $2,15 \%$, respectivamente) no alcanzan 5 puntos sobre 10 en cobertura ( 3,8 y 4,5 respectivamente). Sin embargo, Castilla y León, que dedica un 1,68\%, y Aragón, que dedica un 1,24\% (menos de la mitad que Extremadura) tienen mayor cobertura de prestaciones y servicios sociales (7,3 puntos sobre 10 Castilla y León, 5,9 Aragón). También en términos absolutos, la comparación resulta obvia: Extremadura, con 376,86€ por habitante en 2013 y Castilla-La Mancha, con 369,12€, gastan más que Castilla y León (357,33€) y que Aragón (295,80€); y sin embargo, su oferta de prestaciones y servicios es mucho menor.

Las cuatro comunidades con mejores cocientes entre sus resultados en gasto y cobertura son comunidades con gran protagonismo de las entidades locales 
en servicios sociales: Aragón (0,73), Castilla y León $(0,83)$, Cataluña $(1,13)$, Euskadi $(1,30)$ y Navarra $(1,33)$. Por el contrario, como hemos señalado, las dos comunidades con peor coeficiente son Extremadura $(2,38)$ y Castilla-La Mancha $(2,22)$. Frente al carácter descentralizado de las comunidades con mejores coeficientes, Extremadura, tiene estructuras más centralizadas, especialmente en la gestión de su Sistema para la Autonomía y la Atención a la Dependencia; y Castilla-La Mancha, con la gestión autonómica directa, única en España, de buena parte de las estructuras básicas de servicios sociales (Programa Regional de Acción Social).

Se pone de manifiesto así que existen formas de organización y gestión más eficaces y más eficientes que otras en el desarrollo de los servicios sociales. Y que la descentralización e implicación de las entidades locales es un rasgo común a las comunidades con mayor desarrollo de sus servicios sociales, mientras que, por el contrario, la falta de protagonismo local es común en las comunidades con menor desarrollo en estos servicios. En consecuencia, el protagonismo de las entidades locales y la cooperación entre administraciones ofrece mayor cobertura y mejores resultados, con menos costes.

Unos resultados tan evidentes desmontan el mito de que centralizar la gestión de los servicios sociales contribuye a "la estabilidad presupuestaria, sostenibilidad financiera o eficiencia en el uso de los recursos públicos", como argumenta en la exposición de motivos a la Ley de Racionalización y Sostenibilidad de la Administración Local. Esta centralización, además de ser socialmente negativa, es antieconómica y encarece la gestión del sistema. Salvo, evidentemente, que el objetivo sea desmontar o privatizar servicios sociales. En ese caso, indudablemente, se contribuiría a "la estabilidad presupuestaria, la sostenibilidad finan- ciera" de las administraciones, pero no por la vía de la "eficiencia en el uso de los recursos públicos", ni mucho menos, sino lisa y llanamente a costa de dejar al ciudadano/a sin los servicios más necesarios para sus necesidades básicas de vida y convivencia. Por eso nos preocupan los efectos que puede tener, particularmente en los dos próximos años, dicha Ley, que ha generado un escenario de profunda incertidumbre para los servicios sociales en el ámbito local.

\subsubsection{Evolución de los indicadores de gasto y cobertura}

La tercera aplicación del Índice DEC permite constatar la evolución de cada uno de los indicadores de gasto y cobertura. Ya hemos visto algunos de los gráficos que expresan esta evolución en los indicadores de gasto; de la misma manera se expresa en cada uno de los indicadores de cobertura, a nivel general y en el informe específico de cada comunidad. Cuando se registra la evolución de un indicador en una comunidad autónoma, se compara con la que registra a nivel general, lo que ofrece perspectivas muy interesantes para el análisis de tendencias.

Los Gráficos 13 y 14 son dos ejemplos del registro de evolución de dos indicadores de cobertura, referidos ambos a Euskadi.

El registro de tres años ofrece una perspectiva todavía muy limitada, es evidente, pero es fácil suponer el interés que pueden tener cuando registre series de varios años más. Quizás este registro sistemático de valores de los indicadores de gasto y cobertura sea, en el futuro, una de las principales utilidades del Índice DEC. El análisis de las tendencias que ello va a permitir puede superar limitaciones estructurales del propio Índice.
Gráfico 13. Evolución de la cobertura del Sistema para la Autonomia y la Atención a la Dependencia. Euskadi y conjunto de España, 2011-2013 (\% personas beneficiarias sobre el total de la población)

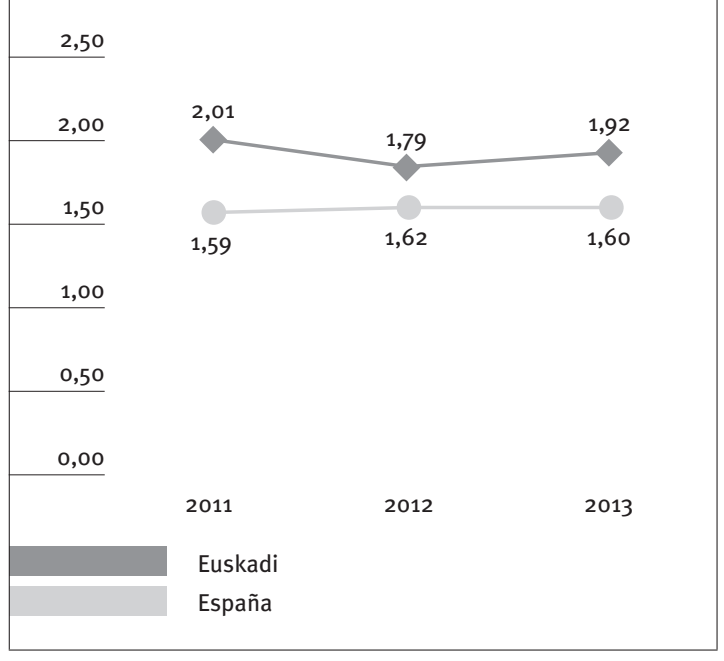

Fuente: Elaboración propia a partir de García et al. (2014).

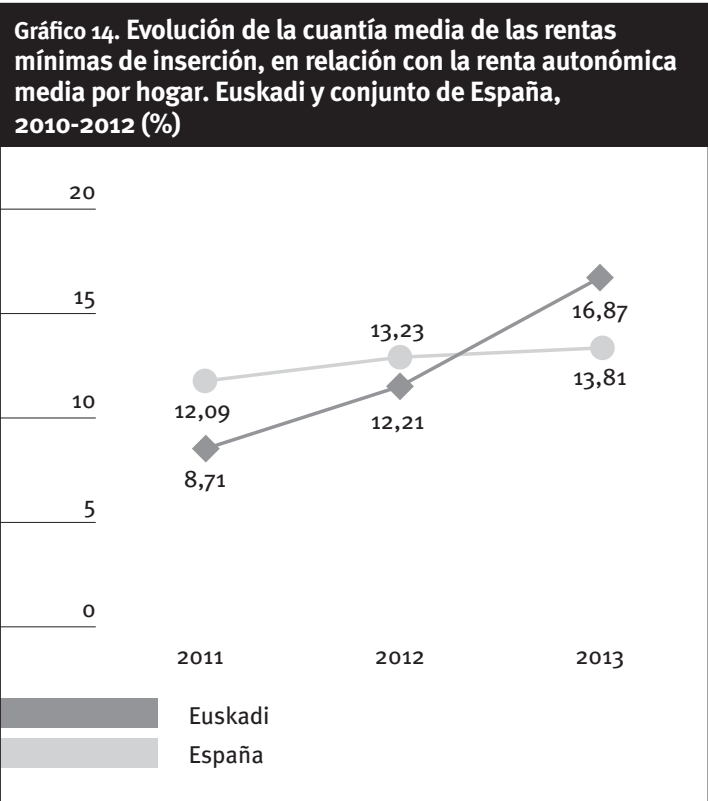

Fuente: Elaboración propia a partir de García et al. (2014). 


\subsection{Recomendaciones}

El informe global del Índice DEC concluye cada año con una serie de recomendaciones, a la vista de los resultados de su aplicación. De la misma manera, el informe específico de cada comunidad autónoma termina con las consiguientes recomendaciones sobre el desarrollo de los servicios sociales en su territorio. El progresivo deterioro de los servicios sociales que constatan los resultados del Índice DEC en 2014, así como las amenazas que se ciernen sobre ellos, han sugerido las siguientes recomendaciones.

\subsubsection{Establecer pactos institucionales entre los Gobiernos autonómicos y las entidades locales para mantener su nivel de competencia en servicios sociales}

La incertidumbre que está generando la Ley de Racionalización y Sostenibilidad de la Administración Local es la mayor amenaza que se cierne actualmente sobre los servicios sociales, que pone en riesgo la continuidad de muchos de ellos, y paraliza y deteriora la capacidad de actuación de las entidades locales en esta materia. Se trata, por tanto, de lograr escenarios de estabilidad basados en acuerdos entre los Gobiernos autonómicos y las entidades locales de su territorio, cuyas claves sean:

- Interpretar de forma amplia el nivel competencial que la citada Ley establece en materia de servicios sociales para las entidades locales ${ }^{5}$.

- Mantener en el ámbito local, vía delegación de competencias, el resto de prestaciones y servicios sociales que configuran la atención primaria en esta materia, y que no encajen en el nivel competencial propio definido en la Ley.

- Establecer acuerdos para el traspaso ordenado de aquellos servicios y prestaciones gestionadas en el ámbito local que deban pasar a competencia autonómica.

- Elaborar, a partir de esas referencias, el plan para la evaluación e implantación de servicios al que obliga la disposición adicional segunda de la Ley.

La aprobación de leyes de nueva generación en aquellas comunidades autónomas que aún no disponen de ellas, así como su desarrollo normativo, y la aprobación o actualización, en su caso, de mapas y planes estratégicos son hoy necesarios para lograr el escenario de estabilidad que los servicios sociales en el ámbito local necesitan.

${ }^{5}$ Un análisis de estos contenidos competenciales puede verse en García Herrero (2014).
3.3.2. Compromiso de recuperar el gasto de las administraciones públicas en servicios sociales al menos hasta los niveles de 2009

Los resultados del Î́ndice DEC en 2014 ponen de manifiesto una caída del gasto en servicios sociales por parte de los Gobiernos autonómicos y de las entidades locales, que sólo en los dos últimos años es del $13,3 \%$. Una reducción tanto más grave cuanto se produce en las circunstancias actuales, con cientos de miles de familias en situaciones de extrema necesidad y grave riesgo de dar el fatídico paso de la pobreza a la exclusión. Por eso es imprescindible un compromiso del conjunto de las administraciones para recuperar el gasto en materia de servicios sociales al menos hasta los niveles en que se encontraba al inicio de la crisis (2009) y, en todo caso, para no realizar ningún nuevo recorte presupuestario en esta materia. El cuestionable objetivo de reducción del gasto público en los momentos actuales no debe realizarse, en ningún caso, a costa de las necesidades más básicas de las personas y las familias más afectadas por la crisis.

Conviene recordar que cada millón de euros invertido en servicios sociales representa sólo una inversión neta de en torno a los 600.000 euros, ya que conlleva unos retornos inmediatos (en el mismo ejercicio presupuestario) cercanos al $40 \%$ (Díaz Díaz, 2011).

Además, la inversión en servicios sociales tiene una gran capacidad de generación de empleo. Cada millón de euros invertido en servicios sociales permite generar entre 26 y 42 empleos directos (Federación Empresarial de Asistencia a la Dependencia, 2010). Pocos sectores económicos pueden exhibir una capacidad como ésta de generación de empleo y riqueza, ya que de manera inmediata la práctica totalidad de la inversión, destinada de forma mayoritaria al pago de salarios de no elevada cuantía, repercute en el consumo, con sus beneficiosos efectos sobre la economía. Asimismo, el empleo en servicios sociales es descentralizado, no deslocalizable y beneficia a sectores de población con dificultades.

\subsubsection{Compromiso de la Administración General del Estado y de las comunidades autónomas de mantener la tasa de reposición en el Sistema para la Autonomía y la Atención a la Dependencia en tanto haya personas con el derecho reconocido a las que no se les esté ofreciendo de manera efectiva la prestación o servicio que les corresponda}

El deterioro del Sistema para la Autonomía y la Atención a la Dependencia ha llegado a tal extremo que, a nivel estatal, ya no se garantiza siquiera la tasa de reposición, es decir, mantener al menos el mismo número de beneficiarios mientras haya personas con derecho a recibir atención por su situación de dependencia, y estén a la espera de recibir los servicios o prestaciones que les corresponde. Esto ocurre, además, en varias comunidades autónomas. 
El compromiso de mantener, al menos, la tasa de reposición debe ir acompañado de otras medidas:

- Integrar el sistema de financiación de la Dependencia en el ámbito de la financiación autonómica (LOFCA) haciendo que la Administración General del Estado contribuya al $50 \%$ de la financiación pública, -ahora no llega ni al $20 \%-$, fomentando una inversión social en servicios profesionales que produzca retornos económicos y sobre el empleo, y simplificando el procedimiento para la concesión de las prestaciones y servicios.

- Cualquier medida de modificación de la Ley $39 / 2006$ que afecte a algunas de sus esencias ha de llevarse a cabo mediante su tramitación, debate y, en su caso aprobación en el Parlamento, sin utilizar el atajo de la modificación a través de decreto. Y debe realizarse, además, con un nivel de consenso similar, al menos, al que se logró en su aprobación.

- Entre tanto, se insta al Gobierno a recuperar la financiación del nivel acordado, reponer el nivel mínimo recortado (13\%), establecer el plazo de atención en seis meses -y no en dos años y medio, como aprobó el actual Gobierno-, por haber sido decisiones que modifican unilateralmente contenidos esenciales de la Ley, y que incumplen compromisos con la ciudadanía y con las propias comunidades autónomas más comprometidas con el desarrollo de la Ley.

\subsubsection{El Estado debe regular las condiciones básicas que garanticen la igualdad de todos los españoles en el ejercicio del derecho al nivel básico de protección social}

Sabemos que una propuesta de estas características generará rechazo en quienes apuestan por una mayor descentralización del Estado. Sin embargo, no podemos por menos que hacerla, a la vista de las extraordinarias diferencias que se constatan en una materia como los servicios sociales, que representa un nivel básico de la protección social. Incluso el Estado más federal tiene elementos que lo cohesionan. Si nadie discutiría la necesidad de unas estructuras de defensa comunes, ¿no es menos importante para la ciudadanía unas referencias básicas comunes en protección social?

Así pues, seguimos planteando la necesidad de que se elabore y apruebe una norma estatal que garantice la igualdad de todos/as los/as ciudadanos/as en el ejercicio del derecho al nivel básico de protección social, y corrija la actual situación de inequidad en el acceso y disfrute de los servicios sociales. Para que esta regulación resulte eficaz en una materia de competencia exclusiva de las comunidades autónomas, consideramos imprescindible que vaya precedida de un proceso de negociación y consenso con éstas, pero que dicho consenso no impida, en última instancia, la responsabilidad de regular las condiciones básicas de igualdad de los españoles, que corresponde constitucionalmente al Estado.
3.3.5. De rentas mínimas de inserción a la garantía de ingresos mínimos

Es preciso llevar a cabo una profunda revisión de las políticas en materia de rentas mínimas de inserción, teniendo en cuenta las necesidades de miles de familias en situaciones económicas desesperadas, con incapacidad para cubrir sus necesidades más básicas. La actual estructura de estas prestaciones, en la mayor parte de las comunidades autónomas, está pensada en un momento histórico caracterizado por la ausencia de políticas activas de empleo, por un nivel de desempleo que no había alcanzado el actual y por un tipo de destinatario en situación de grave exclusión social o riesgo de estarlo. La exigencia del inicio de un proceso de inserción laboral era, en este contexto, razonable, aunque se pagara un alto precio en tiempo de tramitación de las prestaciones.

La elevadísima tasa de desempleo, la destrucción de empleo que continúa, y la modificación del tipo de usuario que precisa de la intervención de los servicios sociales, pero que no precisa apoyo para la inclusión social, porque son personas bien integradas en la sociedad, exigen un cambio de paradigma al pensar en la funcionalidad de estas prestaciones. Se trata, por lo tanto, de poner en marcha prestaciones que, con carácter de derecho subjetivo, garanticen unos ingresos mínimos para cubrir las necesidades básicas, exonerando a los perceptores de la obligación de iniciar un proceso de inserción. Tratando el acompañamiento para la inserción social y laboral como un derecho y no como una obligación, salvo tal vez, en determinadas situaciones crónicas que deberían identificarse claramente.

El cambio en la forma de entender estas prestaciones conllevaría, aparte de un cambio en los destinatarios y los objetivos, una clara mejora en los procesos y tiempos de tramitación, ya que no debería requerirse la existencia de informe técnico alguno. Otro cambio que precisa este tipo de ayudas es que deben ser concebidas como una política de Estado, y no como una responsabilidad exclusiva de cada comunidad autónoma. Hay unos mínimos que deberían ser garantizados para todos los/as ciudadanos/as, vivan donde vivan. Es necesario que el Gobierno, los partidos de la oposición, los sindicatos y las organizaciones sociales empiecen a considerar en serio esta perspectiva.

\subsubsection{La Administración General del Estado debe mantener el Plan Concertado de Prestaciones Básicas de Servicios Sociales de Corporaciones Locales}

Frente al continuo recorte de la partida presupuestaria 26.16.231F. 453 en los Presupuestos Generales del Estado, es necesario un compromiso de la Administración General de recuperar, al menos, su nivel de 2009, en un esfuerzo similar al exigido a comunidades autónomas y entidades locales en sus respectivos presupuestos. Sería un compromiso con el mantenimiento de las estructuras más básicas de los servicios 
sociales, las más próximas a la ciudadanía, sin las cuales el resto del sistema perdería coherencia, eficacia y eficiencia. El mantenimiento y recuperación de este compromiso de cofinanciación debe seguir acompañado de los compromisos de gestión, información y de asistencia técnica que contempla el Plan Concertado.

El Plan mantiene la red de servicios sociales de ámbito local, formada por 50.000 trabajadores/as, y atiende a ocho millones de usuarios/as. Su desmantelamiento supondría un golpe demoledor para los servicios sociales de proximidad, que garantizan el nivel más básico de protección a las personas y familias más perjudicas por la crisis.

\subsubsection{El Ministerio de Sanidad, Servicios Sociales e Igualdad debe articular un Sistema de Información de Servicios Sociales que ofrezca información de alcance público, fiable y actualizado}

Para ello, debe exigir a las comunidades autónomas el cumplimiento de sus obligaciones en esta materia, y condicionar la transferencia de créditos que puedan llevarse a cabo al cumplimiento de esas obligaciones. Debe comprometerse, a su vez, a publicar las estadísticas resultantes dentro de plazos actualizados. En concreto, es urgente que se actualicen las siguientes:

- Plan Concertado de Prestaciones Básicas de Servicios Sociales en Corporaciones Locales (cuyos últimos datos publicados corresponden a 2011).

- Plazas en residencias, centros de día y teleasistencia para personas mayores (últimos datos oficiales correspondientes a 2011).

- Datos globales sobre el servicio de ayuda a domicilio (no existe una información global actualizada de este servicio).

- Centros residenciales y centros de día para personas con discapacidad (no existen datos oficiales).

- Centros y plazas de acogida para mujeres víctimas de violencia de género (no existen datos oficiales).

- Rentas mínimas de inserción (últimos datos oficiales correspondientes a 2012).

\section{Bibliografía}

BARRIGA, L. A. et al. (2014): XIII Dictamen del Observatorio Estatal de la Dependencia, serie Dictámenes del Observatorio Estatal de la Dependencia, Asociación Estatal de Directoras y Gerentes de Servicios Sociales [<http://www. directoressociales.com/documentos/ dictamenes-observatorio.html〉].

DÍAZ DÍAZ, B. (2011): El impacto económico y social de la atención a la dependencia en Cantabria, colección Estudios Sociales, no 11 , Gobierno de Cantabria [<http://www. serviciossocialescantabria.org/uploads/ documentos\%20e\%2oinformes/El\%20 impacto\%2oeconomico\%20y\%20social\%20 de\%2ola\%20atencion $\% 20 a \% 20 l a \% 20$ dependencia\%20en\%20Cantabria.pdf〉].

FEDERACIÓN EMPRESARIAL DE ASISTENCIA A LA DEPENDENCIA (2010): "Estudio sobre los efectos económicos y sociales de una política social orientada a la prestación de servicios y PEVS", Revista de la FED, nㅜ 7 .

GARCÍA, G. et al. (2014): Índice DEC. Índice de Desarrollo de los Servicios Sociales 2014, Asociación Estatal de Directoras y Gerentes de Servicios Sociales [<http://www.directoressociales.com/ documentos/novedades-en-discusi $\% \mathrm{C}_{3} \% \mathrm{~B} 3 \mathrm{n}$. $\mathrm{html}$ ).

GARCÍA HERRERO, G. (coord.) (2014): Contenidos de la competencia local en los servicios sociales en el nuevo marco legal, Asociación de Directoras y Gerentes de Servicios Sociales [<http://www. directoressociales.com/images/documentos/ novedaddiscusion/Competencia\%2olocal. LRSAL\%204\%201\%201.pdf〉]

HERRERO, C.; SOLER, Á.; y VILLAR, A. (2013): La pobreza en España y sus comunidades autónomas 2006-2011, Valencia, Instituto Valenciano de Investigaciones Económicas [rhttp://dx.doi. org/10.12842/poverty_2012〉].

INSTITUTO VALENCIANO DE INVESTIGACIONES ECONÓMICAS (2014): Pobreza en un periodo de crisis económica, serie Capital Humano, nํㅜㄴ 145, Valencia, Instituto Valenciano de Investigaciones Económicas.

ZUBIRI, I. (dir.) (2009): “El impacto económico del gasto en política social de la Diputación Foral de Gipuzkoa", en ETXANIZ, M. et al., Ponencias del proceso de reflexión, Donostia-San Sebastián, Diputación Foral de Gipuzkoa. 